\title{
Communication with our patients, recognition of our peers
}

$\mathrm{P}$ REVIOUSLY IN THIS COLUMN I HAVE BEMOANED THE paucity of rigorous evidence in much of our understanding of the treatment of congenital cardiac anomalies. ${ }^{1}$ It is true that there are few randomised controlled trials for therapeutic interventions in congenital cardiac disease. Most of the evidence we have is observational. Evidence it is, but liable to mislead as it is not randomised or controlled. Rigorous statistical analysis of carefully collected prospective quantitative data is required, and in many specialities such availability has led to radically improved outcomes for patients. Our speciality has yet to embrace whole-heartedly this level of scientific enquiry. It is overdue.

Readers of this edition of Cardiology in the Young may, therefore, be surprised to see a completely different type of research published in its pages. Rempel and colleagues ${ }^{2}$ present a qualitative piece of research into how we communicate with parents of children with hypoplastic heart syndrome. They ask whether the advice that we so often give "treat your child as normal" is indeed helpful. Their conclusion is that parents find the advice reassuring, but it may stand in the way of the child receiving the support it needs for other problems, such as with their growth and development. This is something we need to consider carefully. Reassurance for worried parents, whose child has hypoplastic left heart syndrome, or another complex congenital cardiac anomaly, is valuable. But this consideration needs to be carefully balanced against the fact that false reassurance may reduce the chance of the child receiving necessary support. This insight will certainly make me consider the advice I give.

But, this is qualitative research. It is valid? We are used to assessing the results of quantitative research. How, then, should we interpret a relatively small study without the normal statistical analysis? There are many types of evidence. As I have already pointed out, the evidence we often rely on is far from truly scientifically rigorous. Do qualitative studies, such as this, really have anything to teach us? This question did indeed split our independent reviewers of the article submitted by Rempel and colleagues. ${ }^{2}$ We had a heated debate about whether we should indeed publish it. I leave you to judge for yourself whether the conclusions of this research should influence your practice. To help, Clark has provided an accompanying editorial introducing the technique of qualitative research and how it can be used. ${ }^{3}$ I welcome your feedback about this approach. Should we publish more of this type of article?

Also in this edition of Cardiology in the Young, we explore the phenomenon of the eponym. Evans has provided us with a review of probably the most notable eponym in our discipline, namely the BlalockTaussig shunt. ${ }^{4}$ Eponyms are perhaps as controversial as qualitative research. Some, those who believe that progress is the result of the insights or discoveries of a few heroes, are enthusiasts. Others believe that progress comes form the concerted work of many, and that it is the work of successful teams that leads to progress. While the use of eponyms recognises the contributions of a few, it equally ignores the contributions of the many. Perhaps a more valid reason to criticise eponyms is that often the lesion, condition, or procedure to which they refer becomes confused. Blalock-Taussig, or perhaps more commonly BT, shunt is often used loosely to describe many systemic-to-pulmonary shunts that are very different from the one originally described by Blalock and Taussig. ${ }^{5}$ This lack of precision in the use of eponyms is often annoying, but more importantly it can sometimes put patients at risk. Sloppy use of eponyms is frequent and dangerous. No one should use an eponym unless they know exactly to what it refers. If there is any room for ambiguity, they should not use it at all.

No one can doubt the immense contribution of Alfred Blalock or Helen Taussig to our understanding of the treatment of congenital cardiac anomalies, so whatever the objections to eponyms in general, it is entirely appropriate that they are remembered in the name of what is a common and a life-saving procedure. As Evans points out, nonetheless, the contribution of Vivien Thomas to the development of the shunt was critical, but he does not get recognition in the eponym. The article from 
Bill Evans ${ }^{4}$ is a useful reminder of his contribution. It shows more generally that the stories behind eponyms are often complex, and the contributions to the development of the science of our specialty are often by many who receive little recognition for what they achieve. We should not use them lightly. As Abraham Lincoln said, none of us should worry too much about being recognised, but we should all "strive to be worthy of recognition".

Edward Baker Editor-in-Chief E-mail: ctyeditor@cambridge.org

\section{References}

1. Baker E. From the Editor in Chief. Cardiol Young 2008; 18: $1-2$.

2. Rempel GR, Harrison MJ, Williamson DL. Is "Treat your child normally" helpful advice for parents of survivors of treatment of hypoplastic left heart syndrome? Cardiol Young 2009; 19: doi:10.1017/S1047951109003485.

3. Clark AM. Qualitative research: what it is and what it can contribute to cardiology in the young. Cardiol Young 2009; 19: doi:10.1017/S1047951109003746.

4. Evans W. The Blalock-Taussig shunt: social history of an eponym. Cardiol Young 2009; 19: doi:10.1017/S1047951109003631.

5. Blalock A, Taussig H. Surgical management of malformation of the heart in which there is pulmonary stenosis or pulmonary atresia. JAMA 1945; 128: 189-202. 